\title{
Long-Term Clinical Efficacy and Perioperative Safety of Endoscopic Submucosal Dissection versus Endoscopic Mucosal Resection for Early Gastric Cancer: An Updated Meta-Analysis
}

\author{
Yajie Zhao and Chengfeng Wang $(\mathbb{D}$ \\ Department of Pancreatic and Gastric Surgery, National Cancer Center/Cancer Hospital, \\ Chinese Academy of Medical Sciences and Peking Union Medical College, Beijing 100021, China
}

Correspondence should be addressed to Chengfeng Wang; wangchengfeng62@163.com

Received 18 September 2017; Accepted 10 December 2017; Published 11 January 2018

Academic Editor: Toshimi Chiba

Copyright (c) 2018 Yajie Zhao and Chengfeng Wang. This is an open access article distributed under the Creative Commons Attribution License, which permits unrestricted use, distribution, and reproduction in any medium, provided the original work is properly cited.

\begin{abstract}
Background. To systematically evaluate the safety and efficacy of endoscopic submucosal dissection (ESD) versus endoscopic mucosal resection (EMR) for early gastric cancer (EGC). Methods. We searched the databases of PubMed, Web of Science, EMBASE, and the Cochrane Library from January 2000 to April 2017 and included studies that compared the outcomes of ESD with EMR for EGC. These eligible studies that met the inclusion criteria were screened out and were assessed by two independent investigators. Result. In total, 18 retrospective cohort studies were eligible for analysis. Our results indicated that ESD is more beneficial than EMR in increasing the complete resection rate and en bloc resection rate and decreasing the local recurrence rate. However, ESD prolonged operative time and increased incidence of gastric perforation than EMR. No differences were found in postoperative bleeding rate between the two approaches. Conclusion. Compared with EMR, ESD offers higher complete resection rate, higher en bloc resection rate, and lower local recurrence rate but has prolonged operative time and increased incidence of gastric perfusion. There is no statistical difference in the rate of postoperative bleeding between the two groups. However, the above conclusion needs further verification by well-designed, randomized trials with larger samples and long follow-up periods.
\end{abstract}

\section{Introduction}

Endoscopic mucosal resection (EMR) technique is widely accepted as standard treatment for early gastric cancer (EGC) [1]. It declares that the technique of endoscopic mucosal resection is indicated for early gastric cancer with no lymph node metastasis. EMR is widely accepted by endoscopists for its advantages of being minimally invasive, cost effective, and well tolerated and offering good quality of postoperative life $[2,3]$. Despite the convenience of EMR, larger lesions cannot be completely removed by EMR in one attempt; therefore, the entire pathologic specimen cannot be retrieved, and a proper treatment decision cannot be made by clinicians through precise pathological examination, which leads to a potentially high risk of local tumor recurrence or excessive treatment. To overcome the disadvantages of EMR, ESD is used for the resection of large lesions [4]. ESD technology can directly remove tumors from the submucosal layer. However, owing to larger wound size and difficulty in performing the technique, ESD has higher incidence of postoperative complications such as postoperative bleeding and perforation. Some studies have compared the application of EMR and ESD, but with inconsistent results. There are few meta-analyses comparing the efficacy and safety of endoscopic submucosal dissection with endoscopic mucosal resection for EGC. Therefore, we performed a meta-analysis to assess the efficacy and safety of ESD and EMR in EGC and provide clinical evidence for endoscopic treatment of early gastric cancer.

\section{Materials and Methods}

2.1. Literature Search. We searched the databases of Web of Science, PubMed, EMBASE, and the Cochrane Library for journal articles published from January 2000 to April 2017. 


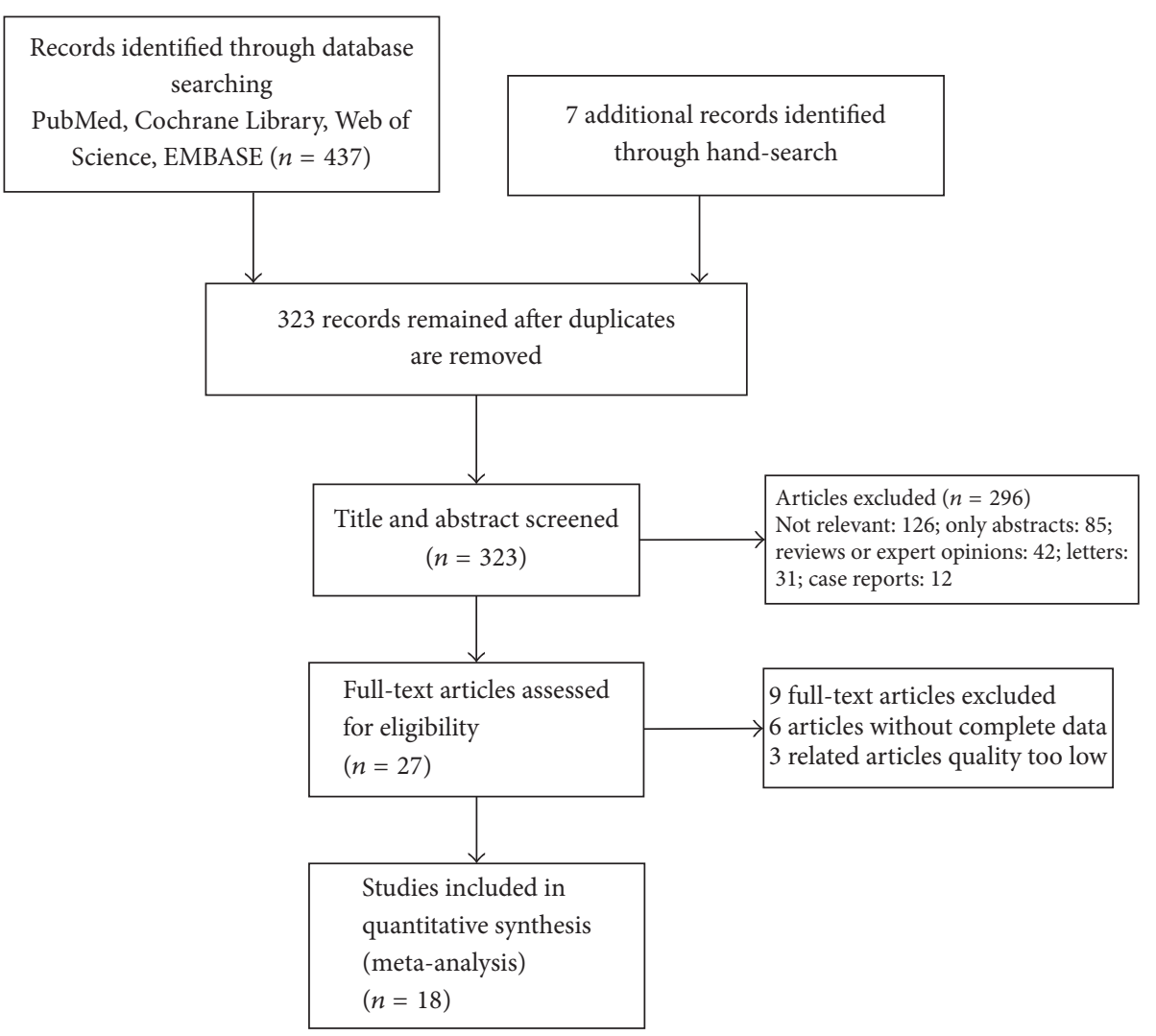

FIGURE 1: Flow diagram.

The following search terms were used: "ESD” or "endoscopic mucosal resection" and "endoscopic mucosal resection" or "EMR" and "early gastric cancer" or "EGC". Both free terms and $\mathrm{MeSH}$ words were included. There was no language restriction and two independent researchers performed this search. Final inclusion was determined by consensus. The results of the search strategy are shown in Figure 1.

2.2. Inclusion Criteria. The following studies were included: (1) those in which the included patients were diagnosed with EGC based on histology; (2) studies that were conducted to compare ESD and EMR for EGC; (3) those where the endpoints included therapeutic effect index and postoperative complications; and (4) those where if the same data had been published multiple times, the latest publication was considered.

2.3. Exclusion Criteria. The following studies were excluded: (1) those in which the detailed surgical type was not reported;

(2) those that had participants without early gastric cancer, instead with adenoma, precancerous lesions, or other gastric lesions; (3) studies referring to recurrent early gastric cancer; (4) those that had no data regarding therapeutic effects or complications and those in which the study outcomes did not include complete or available perioperative outcomes and postoperative data; (5) those which reported data used in a later study; and (6) case reports, abstracts, letters, comments and reviews or guideline articles without original data, and studies that presented insufficient data.

2.4. Data Extraction. The following detailed data were extracted by the two independent investigators: authors; year of publication; country; study design; surgery type; number of patients; and the following clinical data: (1) operation time: the time from marking to complete removal of the tumor and including the time for hemostasis; (2) en bloc resection: removing the tumor in one piece without fragmentation; (3) complete resection: the histologic examination shows the lateral margins being tumor-free $\geqslant 2 \mathrm{~mm}$ and the vertical margins being tumor-free $\geqslant 0.5 \mathrm{~mm}$; (4) postoperative bleeding: postoperative hematemesis or melena needs an endoscopic hemostatic procedure; (5) perforation: free air was seen on abdominal radiograph or endoscopic observation of mesenteric fat after the operation. (6) Local recurrence: the same histological type of cancer was found at the resection site more than 6 months after the operation.

2.4.1. Statistical Analysis. Meta-analysis was conducted with Review Manager (version 5.3.0) software. Odds Ratios (ORs) were used to analyze the dichotomous variables and 95\% confidence interval (CI) values were reported. The MantelHaenszel, Chi-square, and $I^{2}$ tests were used to test the heterogeneity between studies. If $I^{2}>50 \%$, this suggested significant heterogeneity; a random effects model was applied. 
TABLE 1: The characteristics of all the included studies.

\begin{tabular}{|c|c|c|c|c|c|c|}
\hline Author & Year & Country & Study type & Group & Patients Number & Study quality \\
\hline \multirow{2}{*}{ Tanabe et al. [5] } & \multirow{2}{*}{2014} & \multirow{2}{*}{ Japan } & \multirow{2}{*}{ Retro } & EMR & 359 & \multirow[t]{2}{*}{5} \\
\hline & & & & ESD & 421 & \\
\hline \multirow{2}{*}{ Okada et al. [6] } & \multirow{2}{*}{2012} & \multirow{2}{*}{ Korea } & \multirow{2}{*}{ Retro } & EMR & 45 & \multirow{2}{*}{5} \\
\hline & & & & ESD & 31 & \\
\hline \multirow{2}{*}{ Ahn et al. [7] } & \multirow{2}{*}{2011} & \multirow{2}{*}{ Korea } & \multirow{2}{*}{ Retro } & EMR & 537 & \multirow{2}{*}{5} \\
\hline & & & & ESD & 833 & \\
\hline \multirow{2}{*}{ Park et al. [8] } & \multirow{2}{*}{2010} & \multirow{2}{*}{ Korea } & \multirow{2}{*}{ Retro } & EMR & 50 & \multirow{2}{*}{5} \\
\hline & & & & ESD & 189 & \\
\hline \multirow{2}{*}{ Watanabe et al. [9] } & \multirow{2}{*}{2006} & \multirow{2}{*}{ Japan } & \multirow{2}{*}{ Retro } & EMR & 146 & \multirow{2}{*}{7} \\
\hline & & & & ESD & 219 & \\
\hline \multirow{2}{*}{ Shimura et al. [10] } & \multirow{2}{*}{2007} & Japan & Retro & EMR & 22 & 5 \\
\hline & & tapant & स्था० & ESD & 40 & \\
\hline Nakamoto et al [11] & 2009 & Japan & Retro & EMR & 80 & 5 \\
\hline 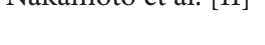 & 2007 & tapant & Netio & ESD & 122 & 年 \\
\hline Catalano et al. [12] & 2009 & Italy & Retro & EMR & 36 & 7 \\
\hline 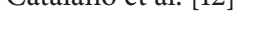 & & Hery & 14tio & ESD & 12 & \\
\hline Min et al [13] & 2009 & Korea & Retro & EMR & 103 & 7 \\
\hline Timl et al. [D] & & & & ESD & 243 & r \\
\hline Hoteva et al [14] & 2009 & Japan & Retro & EMR & 328 & 7 \\
\hline Hoteya el al. [14] & 2009 & Japail & Netro & ESD & 572 & $\gamma$ \\
\hline Shimura et al. [10] & 2007 & Japan & Retro & EMR & 48 & 9 \\
\hline & & & & ESD & 59 & \\
\hline Hoteva et al [15] & 2007 & Japan & Retro & EMR & 350 & 7 \\
\hline Hoteya etal. [D] & 2007 & Japan & netro & ESD & 304 & $\gamma$ \\
\hline Oda et al. [16] & 2006 & Japan & Retro & EMR & 411 & 7 \\
\hline Hia te ar. $[10]$ & 2000 & 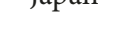 & terto & ESD & 303 & \\
\hline Oka et al [17] & 2006 & Janan & Retro & EMR & 825 & 9 \\
\hline Ura el al. [1/] & 2000 & Japant & Netio & ESD & 195 & J \\
\hline Choi et al. [18] & 2006 & Japan & Retro & EMR & 33 & 7 \\
\hline CIIU1 el di. $[10]$ & 2000 & Japant & Ketio & ESD & 33 & $\gamma$ \\
\hline Watanabe et al [9] & 2006 & Japan & Retro & EMR & 125 & 7 \\
\hline 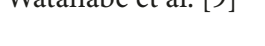 & 2000 & tapant & स्थात & ESD & 120 & r \\
\hline Odashima et al. [19] & 2006 & Japan & Retro & EMR & 80 & 7 \\
\hline & 2000 & 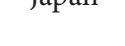 & Netio & ESD & 57 & \\
\hline Yokoi et al. [20] & 2006 & Japan & Retro & EMR & 18 & 7 \\
\hline & & & & ESD & 46 & r \\
\hline
\end{tabular}

$E M R$ = endoscopic mucosal resection, ESD = endoscopic submucosal dissection, and the Newcastle-Ottawa System: the quality of the nonrandomized studies was assessed by using this system, and the quality of the studies was evaluated by examining three items: patient selection, comparability of groups, and assessment of outcome.

If $I^{2}<50 \%$, this suggested not significant heterogeneity; a fixed effects model was applied. If $P<0.05$, this considered statistical significance. Funnel plots were used to evaluate potential publication bias.

2.4.2. Characteristics of the Included Studies and Quality Assessment. 18 retrospective cohort studies were included in this meta-analysis. The total included patients were 7395 , of whom 3596 were EMR group and 3799 were ESD group. The detailed characteristics of all the included studies are shown in Table 1. The observational clinical studies (OCS) were scored based on the Newcastle-Ottawa Scale (NOS) System that included assessments of selection, comparability, and exposure or outcome. Each study was given score of 9 in total; if the total score was $\geq 7$, the OCS was considered to be of high quality.

\section{Meta-Analysis Results}

3.1. Operation Time. Eight studies reported the operation time. The result showed that the ESD group was associated with longer operative times than the EMR group $(\mathrm{OR}=$ -49.86; 95\% CI, -71.62--28.10; $\left.P<0.00001 ; I^{2}=99 \%\right)$; a random effect model was applied (Figure 2).

3.2. En Bloc Resection Rate. Thirteen studies reported on the en bloc resection rate. The analysis showed a higher rate of en bloc resection in the ESD group than in the EMR group (OR 


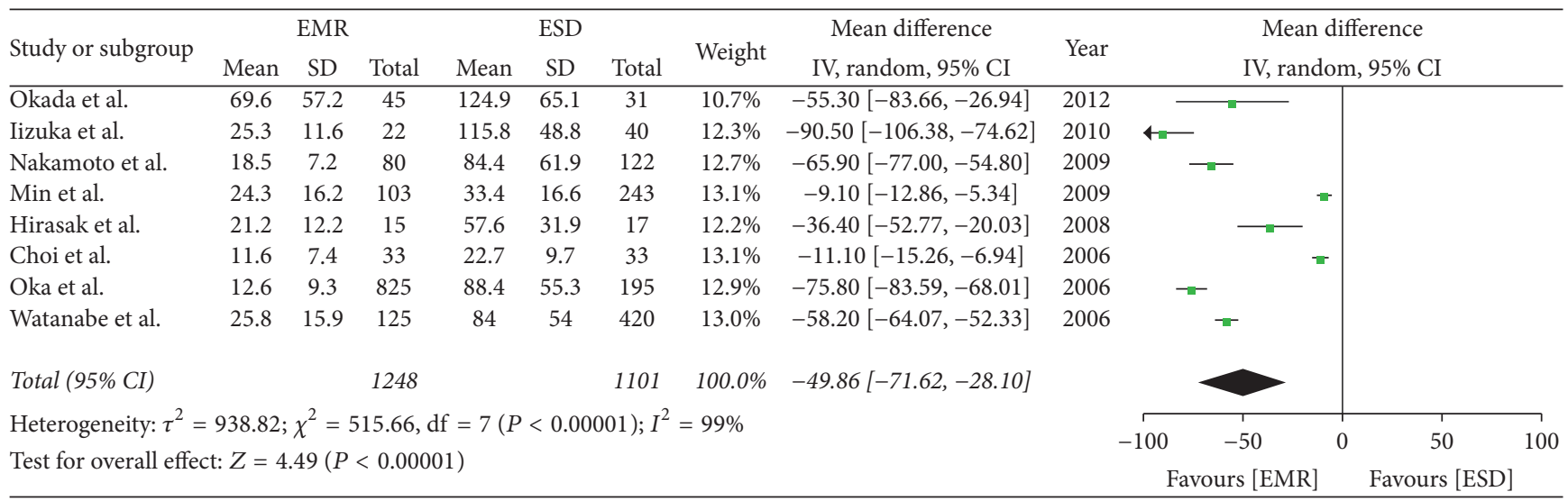

FIgURE 2: Meta-analysis of operation time.

\begin{tabular}{|c|c|c|c|c|c|c|c|c|c|c|c|}
\hline \multirow{3}{*}{$\begin{array}{l}\text { Study or subgroup } \\
\text { Okada et al. }\end{array}$} & \multicolumn{2}{|c|}{ EMR } & \multicolumn{2}{|c|}{ ESD } & \multirow{2}{*}{ Weight } & \multicolumn{2}{|l|}{ Odds Ratio } & \multicolumn{4}{|c|}{ Odds Ratio } \\
\hline & \multirow{2}{*}{$\frac{\text { Events }}{17}$} & \multirow{2}{*}{$\begin{array}{c}\text { Total } \\
45\end{array}$} & \multirow{2}{*}{ Events } & \multirow{2}{*}{$\begin{array}{c}\text { Total } \\
31\end{array}$} & & \multirow{2}{*}{$\frac{\text { M-H, fixed, 95\% CI }}{0.18[0.06,0.50]}$} & \multirow{2}{*}{$\begin{array}{l}\text { Year } \\
2012\end{array}$} & \multicolumn{4}{|c|}{ M-H, fixed, 95\% CI } \\
\hline & & & & & $2.2 \%$ & & & & $\longrightarrow$ & & \\
\hline Ahn et al. & 377 & 537 & 802 & 833 & $23.8 \%$ & $0.09[0.06,0.14]$ & 2011 & & $\rightarrow$ & & \\
\hline Park et al. & 32 & 50 & 164 & 189 & $3.1 \%$ & $0.27[0.13,0.55]$ & 2010 & & $\longrightarrow$ & & \\
\hline Catalano et al. & 26 & 36 & 11 & 12 & $0.6 \%$ & $0.24[0.03,2.08]$ & 2009 & & & & \\
\hline Nakamoto et al. & 43 & 80 & 115 & 122 & $5.3 \%$ & $0.07[0.03,0.17]$ & 2009 & & 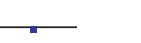 & & \\
\hline Min et al. & 80 & 103 & 233 & 243 & $3.9 \%$ & $0.15[0.07,0.33]$ & 2009 & & . & & \\
\hline Hirasak et al. & 11 & 15 & 17 & 17 & $0.6 \%$ & $0.07[0.00,1.49]$ & 2008 & $\longleftarrow$ & & & \\
\hline Shimura et al. & 15 & 48 & 52 & 59 & $4.1 \%$ & $0.06[0.02,0.17]$ & 2007 & & - & & \\
\hline Hoteya et al. & 219 & 350 & 294 & 304 & $14.9 \%$ & $0.06[0.03,0.11]$ & 2007 & & -- & & \\
\hline Yokoi et al. & 0 & 18 & 41 & 46 & $3.0 \%$ & $0.00[0.00,0.07]$ & 2006 & $\longleftarrow$ & & & \\
\hline Oka et al. & 347 & 825 & 162 & 195 & $19.3 \%$ & $0.15[0.10,0.22]$ & 2006 & & - & & \\
\hline Oda et al. & 230 & 411 & 281 & 303 & $18.1 \%$ & $0.10[0.06,0.16]$ & 2006 & & $\rightarrow$ & & \\
\hline Choi et al. & 25 & 33 & 33 & 33 & $1.1 \%$ & $0.04[0.00,0.81]$ & 2006 & $\longleftarrow$ & & & \\
\hline Total $(95 \%$ CI) & & 2551 & & 2387 & $100.0 \%$ & $0.10[0.09,0.13]$ & & & 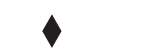 & & \\
\hline Total events & 1422 & & 2229 & & & & & & & & \\
\hline \multicolumn{8}{|c|}{ Heterogeneity: $\chi^{2}=23.13, \mathrm{df}=12(P=0.03) ; I^{2}=48 \%$} & 0.01 & 0.1 & 1 & 100 \\
\hline \multicolumn{8}{|c|}{ Test for overall effect: $Z=23.14(P<0.00001)$} & & rours [EMR] & Favours & \\
\hline
\end{tabular}

FigUre 3: Meta-analysis of en bloc resection rate.

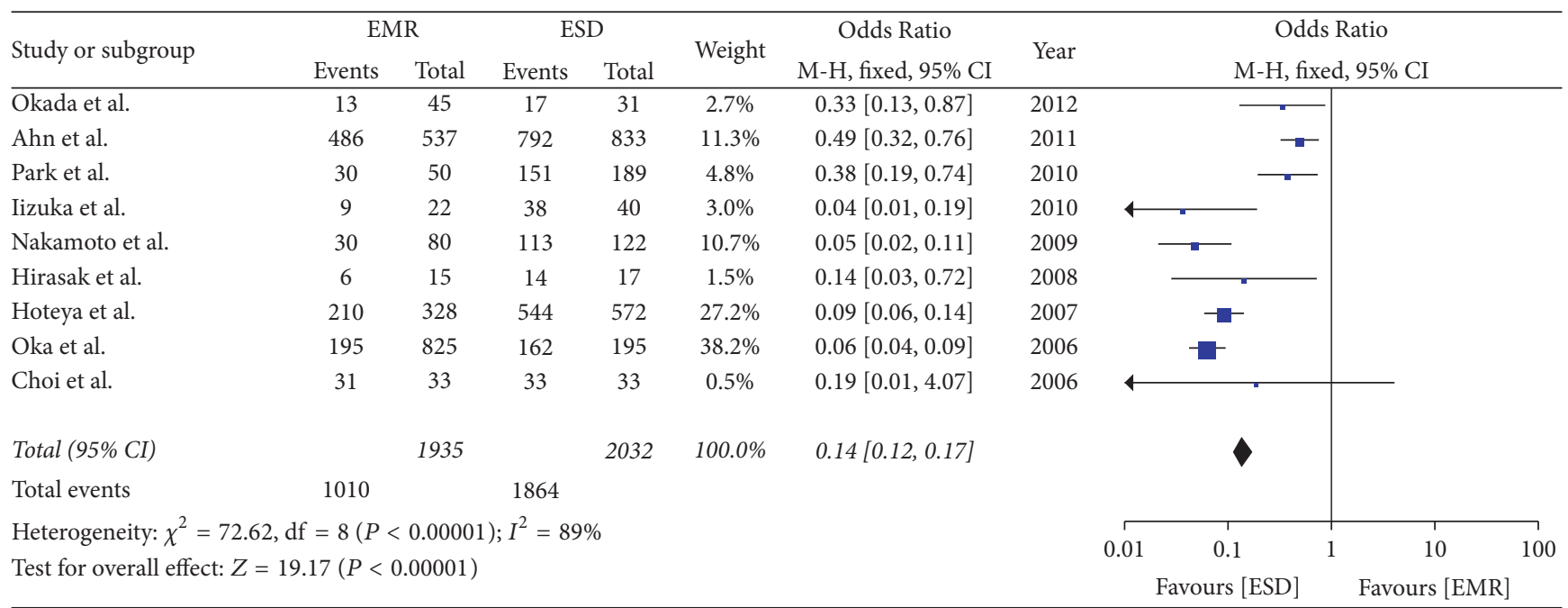

FIGURE 4: Meta-analysis of complete resection rate. 


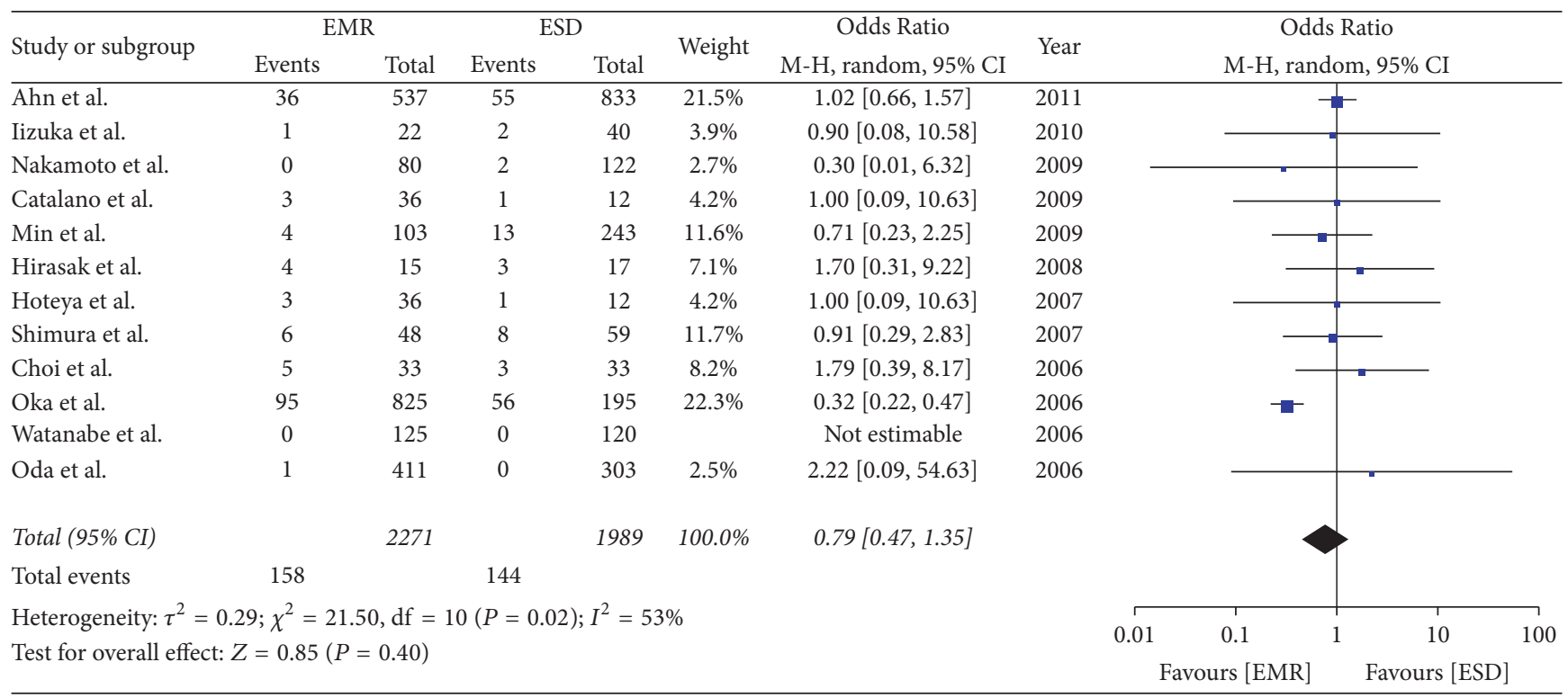

FIGURE 5: Meta-analysis of postoperative bleeding.

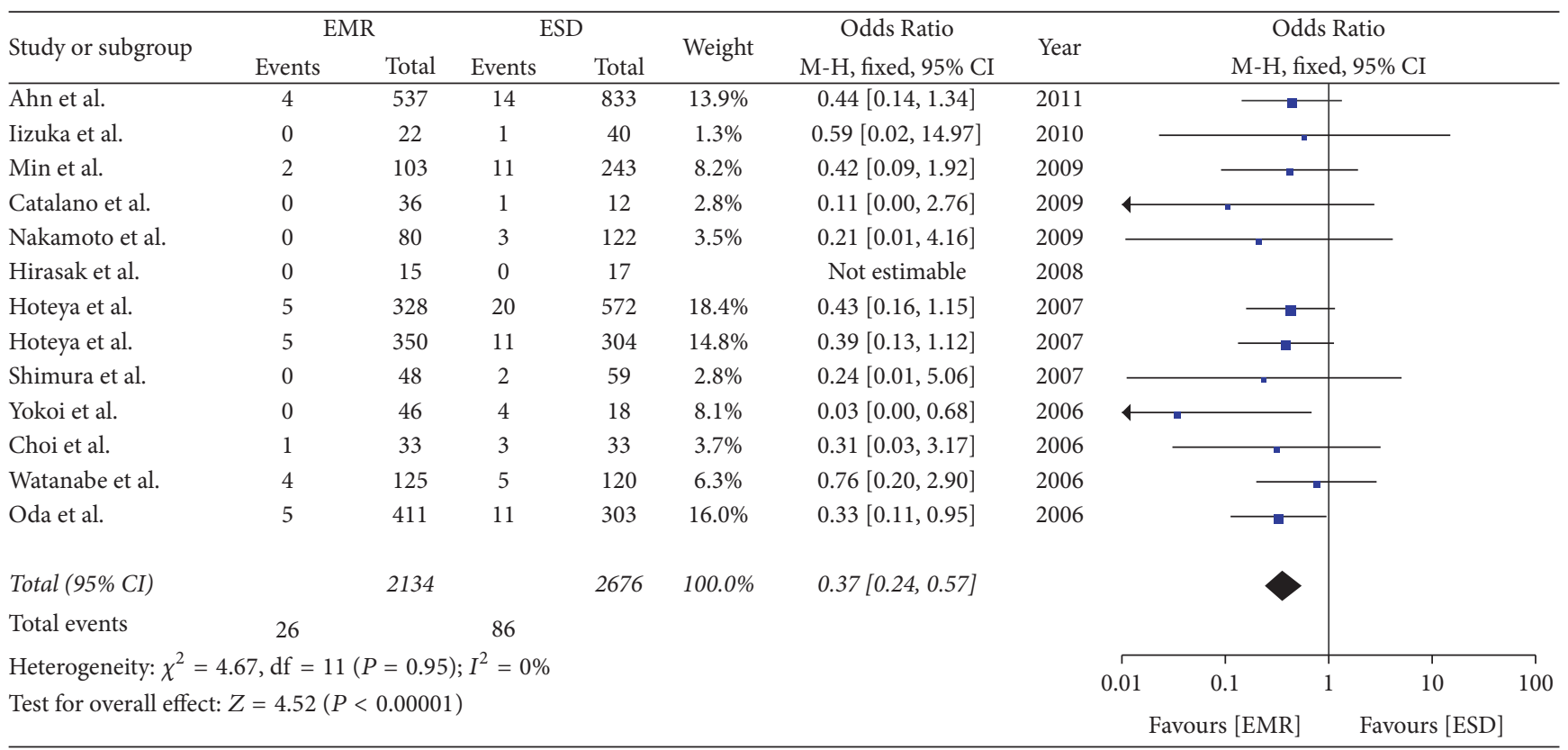

FIGURE 6: Meta-analysis of incidence of perforation.

$=0.10 ; 95 \%$ CI, 0.09-0.13; $\left.P<0.00001, I^{2}=48 \%\right)$; hence, $\mathrm{a}$ fixed effect model was applied (Figure 3 ).

3.3. Complete Resection Rate. Nine studies reported on the complete resection rate. The meta-analysis showed the rate of complete resection was higher in the ESD group than in the EMR group $\left(\mathrm{OR}=0.14 ; 95 \% \mathrm{CI}, 0.07-0.29 ; P<0.00001 ; I^{2}=\right.$ $89 \%)$; hence, a random effect model was applied (Figure 4 ).

3.4. Postoperative Bleeding. Twelve included studies reported on postoperative bleeding. No statistical difference was seen with respect to postoperative bleeding rates between the two groups (OR = 0.79; 95\% CI, 0.47-1.35; $P=0.40 ; I^{2}=53 \%$ ); hence, a random effect model was applied (Figure 5).

3.5. Incidence of Perforation. Thirteen included studies reported on the incidence of perforation. The meta-analysis showed that the incidence of perforation was higher in the ESD group than EMR group (OR = 0.37; 95\% CI, 0.24-0.57; $\left.P<0.00001 ; I^{2}=0 \%\right)$; hence, a fixed effect model was applied. There was a significant difference between the two groups (Figure 6). 


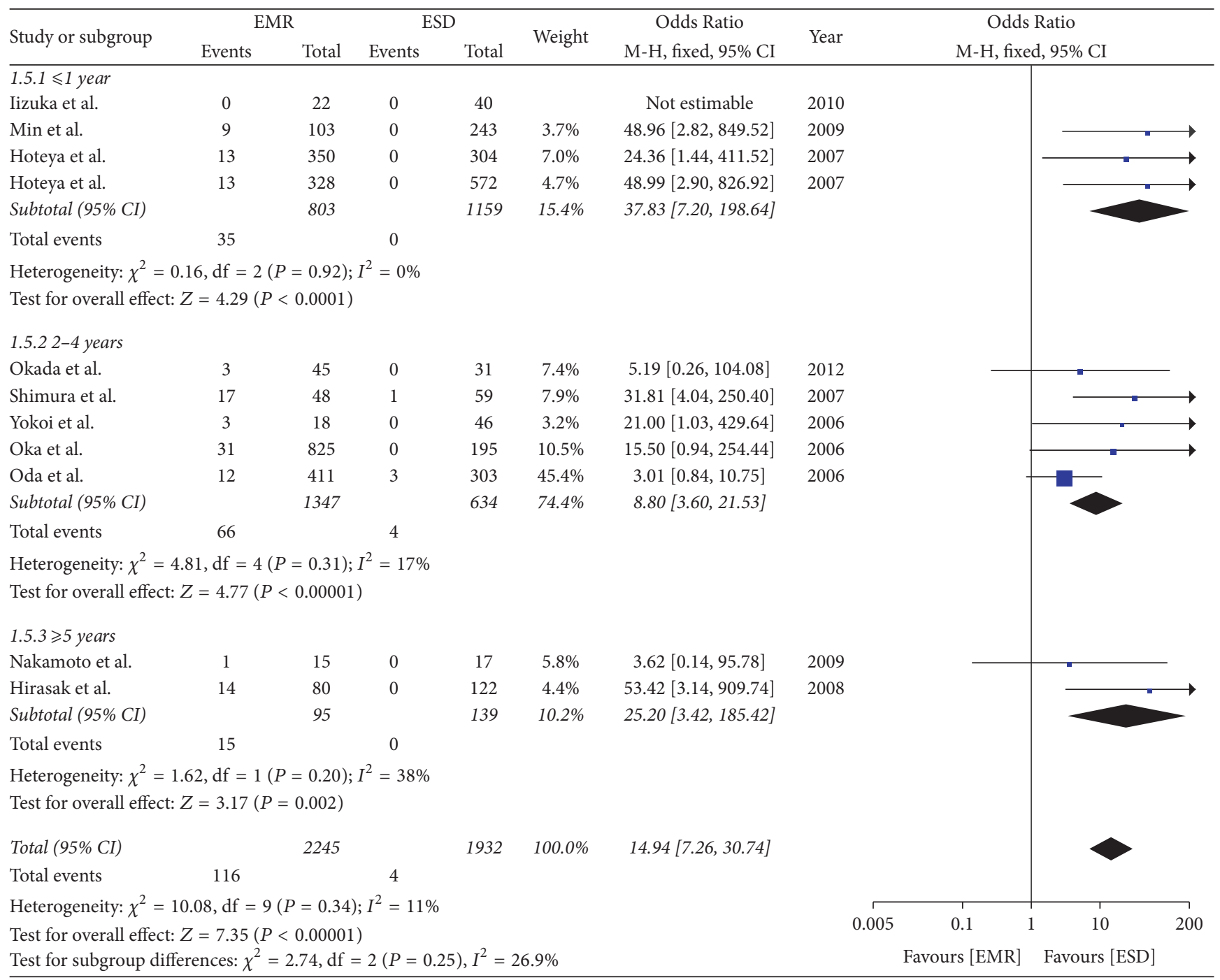

FIGURE 7: Meta-analysis of local recurrence rate.

3.6. Local Recurrence Rate. Four studies compared the local recurrence rate of postoperative time $\leqslant 1$ year. The metaanalysis showed the rate of local recurrence in the ESD group was lower than in the EMR group (OR $=37.83$; 95\% CI, 7.20-198.64; $\left.P<0.0001 ; I^{2}=0 \%\right)$. Five studies compared the recurrence rate of postoperative time $>2$ years but $<4$ years and found that the local recurrence rate in the ESD group was lower than in the EMR group $(\mathrm{OR}=8.80 ; 95 \% \mathrm{CI}, 3.60-21.53$; $\left.P<0.00001 ; I^{2}=17 \%\right)$. Two studies compared the recurrence rate of postoperative time $\geqslant 5$ years and found that the rate was lower in the ESD group than in the EMR group $(\mathrm{OR}=$ 25.20; 95\% CI, 3.42-185.42; $P=0.002 ; I^{2}=38 \%$ ); a fixed effect model was applied (Figure 7).

\section{Subgroup of Meta-Analysis}

4.1. Subgroup Analysis of the En Bloc Rate. Four studies compared the rate of en bloc for lesions $<10 \mathrm{~mm}$. The metaanalysis showed the rate of en bloc for lesions $<10 \mathrm{~mm}$ in the ESD group was higher than in the EMR group $(\mathrm{OR}=$ 0.22; 95\% CI, 0.06-0.81; $\left.P=0.02 ; I^{2}=63 \%\right)$. Three studies compared the en bloc rate for lesions $>10 \mathrm{~mm}$ but $<20 \mathrm{~mm}$ and found that the rate of en bloc in the ESD group was higher than in the EMR group $(\mathrm{OR}=0.05$; 95\% CI, 0.02-0.12; $\left.P<0.00001 ; I^{2}=50 \%\right)$. Two studies compared the en bloc rate for lesions $>20 \mathrm{~mm}$ and found that it was higher in the ESD group than in the EMR group $(\mathrm{OR}=0.03 ; 95 \% \mathrm{CI}$, $\left.0.01-0.07 ; P<0.00001 ; I^{2}=0 \%\right)$; a random effect model was applied (Figure 8).

4.2. Subgroup Analysis of Complete Resection Rate. Four studies compared the complete resection rate for lesions $<10 \mathrm{~mm}$. The meta-analysis showed the rate of complete resection in the ESD group was higher than in the EMR group (OR $=0.12 ; 95 \%$ CI, 0.02-0.62; $P=0.01 ; I^{2}=71 \%$ ). Three studies compared the rate of complete resection for lesions $>10 \mathrm{~mm}$ but $<20 \mathrm{~mm}$ and found that the rate in the ESD group was higher than in the EMR group $(\mathrm{OR}=0.07 ; 95 \% \mathrm{CI}$, 


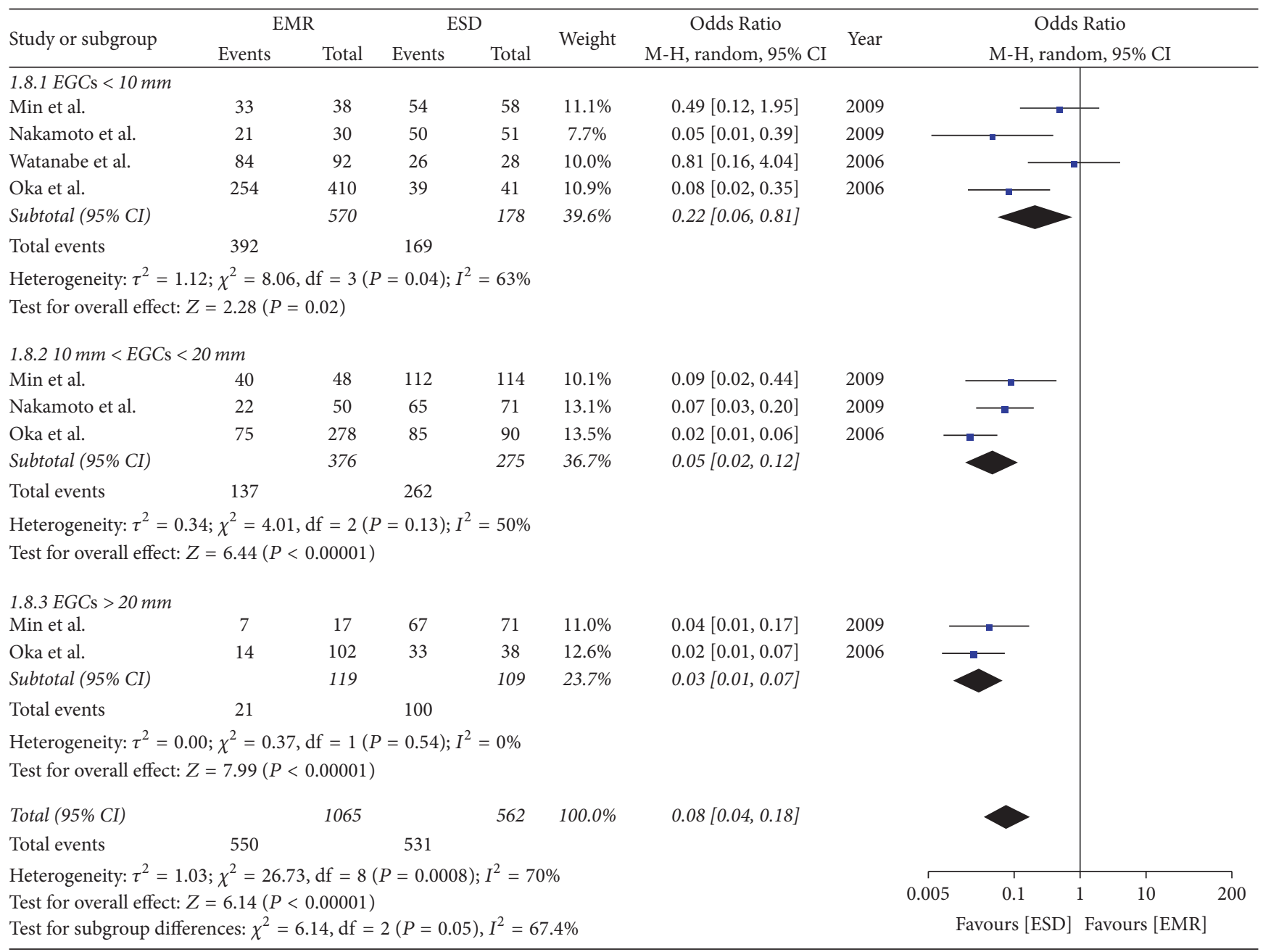

FIGURE 8: Subgroup analysis of the en bloc rate.

0.01-0.87; $\left.P=0.04 ; I^{2}=93 \%\right)$. Two studies compared the rate of complete resection for lesions $>20 \mathrm{~mm}$ and showed the rate of complete resection was higher in the ESD group than in the EMR group $(\mathrm{OR}=0.05 ; 95 \% \mathrm{CI}, 0.00-0.61 ; P=0.02$; $I^{2}=88 \%$ ); a random effect model was applied (Figure 9).

\section{Publication Bias}

Deviation from this shape can indicate publication bias. There was no evident asymmetry in the funnel plots (Figure 10), suggesting a low probability of publication bias.

\section{Discussion}

EMR is widely used treatment for early gastric cancer. However, this kind of technique is with a high local recurrence rate for incomplete resection. In order to overcome this problem, endoscopic submucosal dissection was developed to resected larger lesions that could not be removed using the EMR technique. Although ESD is a new and exciting technology, the technique of ESD is difficult and needs to acquire skills in manipulating treatment devices. Therefore, a large learning gap exists among different endoscopists. What is more, the cost of ESD is higher. The meta-analysis showed longer operation time in ESD group than in the EMR group. ESD is technically difficult and time-consuming mainly because of complex procedures. Intraoperative bleeding sometimes prolongs the time of operation, although bleeding during the operation is sometimes inevitable. Effectively controlling intraoperative bleeding and reducing intraoperative bleeding are the biggest challenge. With growing skill and experience, the operation time of ESD may be reduced.

Postoperative bleeding is a common complication of endoscopic therapy. The results of previous studies have indicated that the rate of postoperative bleeding in ESD is higher than that of EMR, and the reported postoperative bleeding rates varied across studies, although this metaanalysis showed that there was no significant difference in postoperative bleeding rate between the two groups. Perforation is another common complication of endoscopic treatment. It may be related to the size of the lesion or the ulceration. In general, lesion size $>3 \mathrm{~cm}$, ulceration, and unskillful operation increase the risk of perforation. This result of this meta-analysis showed that the rate of perforation 


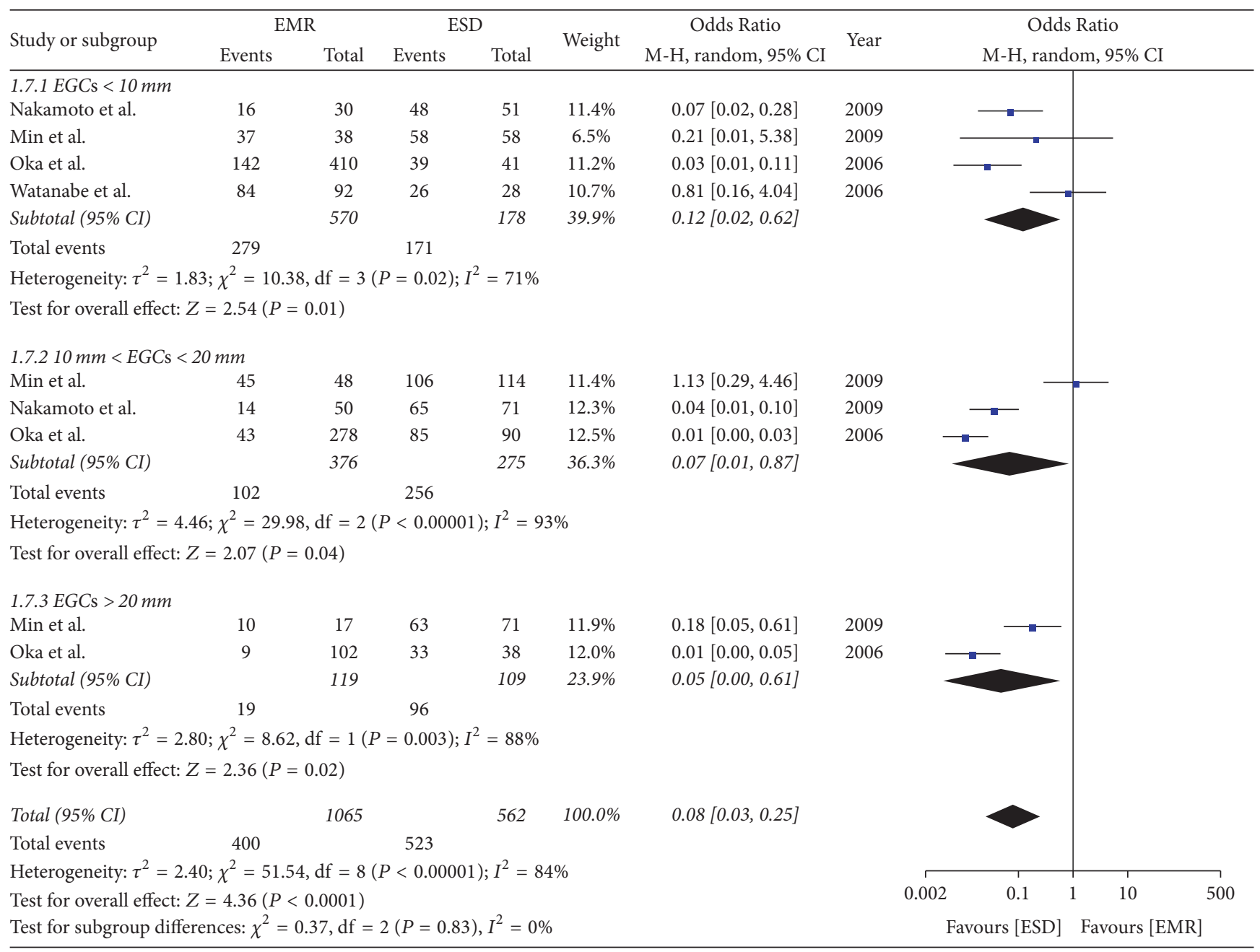

FIGURE 9: Subgroup analysis of complete resection rate.

was higher in the ESD group. In most cases, the perforation was small and did not need surgical treatment. With the development of technologies, the procedural bleeding and perforation may be reduced.

ESD showed advantages regarding effect outcomes. This meta-analysis showed higher rate of en bloc resection and complete resection in ESD group than in EMR group. As the complete resection rate and en bloc resection rate were limited to the lesion size, we performed subgroup analysis according to the tumor size in order to decrease the heterogeneity, This subgroup analysis showed a superior complete resection rate and en bloc resection rate in the ESD group not only for lesions $>10 \mathrm{~mm},<20 \mathrm{~mm}$, and $>20 \mathrm{~mm}$, but also for the lesions $<10 \mathrm{~mm}$. En bloc resection will have technical advantage in procuring the entire pathologic specimen and providing accurate histopathologic evaluation, making it possible to increase the rate of complete resection. Complete resection is beneficial for achieving a negative tumor margins. Therefore, ESD has a technical advantage in achieving a negative tumor margin and reducing the local recurrence rate. The results of this meta-analysis also show the lower rate of local recurrence in the ESD group than EMR group in postoperative time $\leq 1$-year, $>2$-year, $<4$-year, and $\geq 5$-year subgroup.

There are several limitations in this meta-analysis. First, this meta-analysis included only a single western study from Italy. Therefore, the conclusion may not apply in western countries. Second, all included studies in this analysis are observational clinical studies, which may have affected the results. Finally, not all studies provide clear definitions or criteria for any project, so the outcome may be more or less affected. Another potential limitation is that operation experience and methods used at different hospitals and specialist centers could have produced different outcomes and increased the heterogeneity among the included studies.

\section{Conclusions}

ESD showed advantages compared with EMR regarding the high rate of en bloc resection and complete resection and low local recurrence rate, but also having higher rates of perforation and extended operation time; the perforation was usually small and having surgical treatment was not 


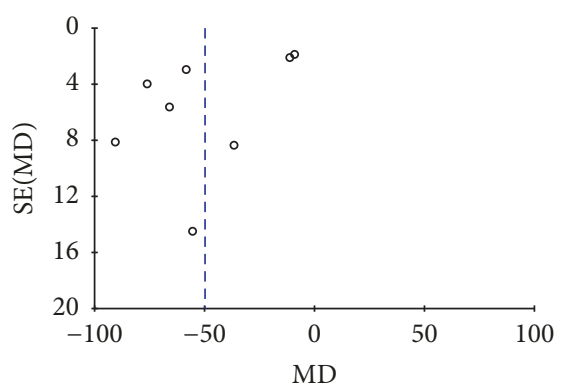

(a)

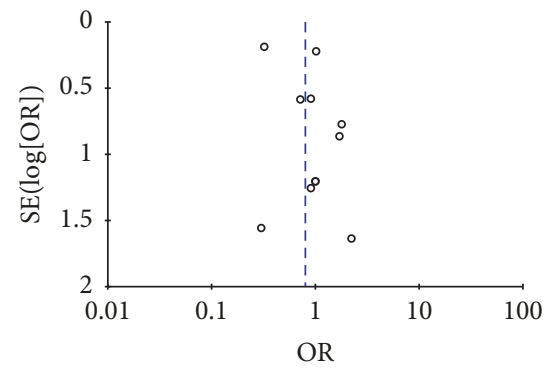

(d)

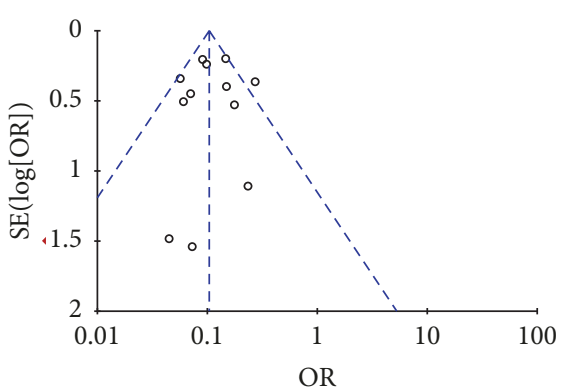

(b)

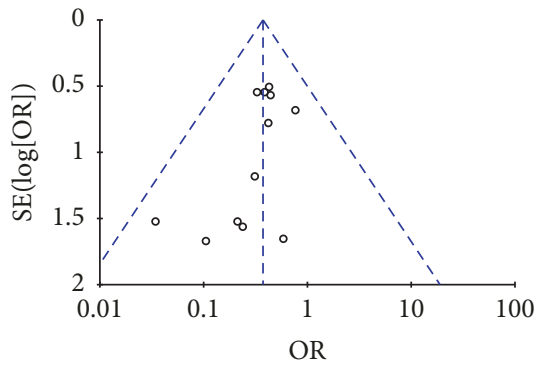

(e)

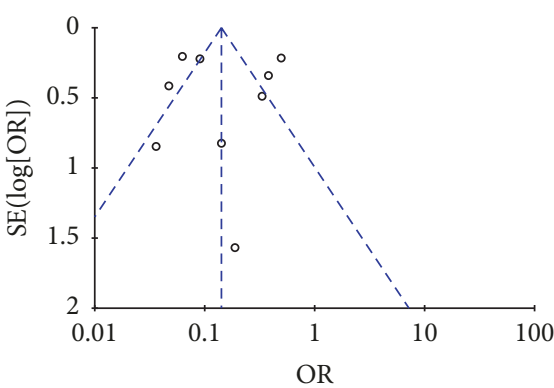

(c)

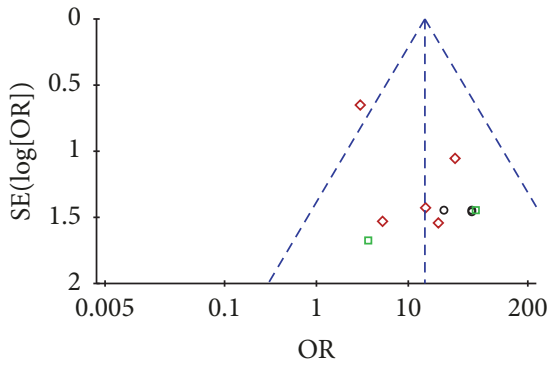

Subgroups

$0 \leqslant 1$ year $\diamond 2-4$ years

$\square \geqslant 5$ years

(f)

FIGURE 10: Funnel plots were created to assess the publication bias in our meta-analysis. In the absence of publication bias, it assumes that studies with high precision will be plotted near the average, and studies with low precision will be spread evenly on both sides of the average, creating a roughly funnel-shaped distribution. (a) Operation time. (b) En bloc resection rate. (c) Complete resection rate. (d) Postoperative bleeding. (e) Incidence of perforation. (f) Recurrence rate.

necessary. The results should be confirmed by large samples and randomized trials from different regions of the world.

\section{Conflicts of Interest}

The authors declare that there are no conflicts of interest regarding the publication of this paper.

\section{References}

[1] M. Tada, A. Murakami, M. Karita, H. Yanai, and K. Okita, "Endoscopic resection of early gastric cancer," Endoscopy, vol. 25, no. 7, pp. 445-450, 1993.

[2] B. J. Rembacken, T. Gotoda, T. Fujii, and A. T. R. Axon, "Endoscopic mucosal resection," Endoscopy, vol. 33, no. 8, pp. 709-718, 2001.

[3] R. M. Soetikno, T. Gotoda, Y. Nakanishi, and N. Soehendra, "Endoscopic mucosal resection," Gastrointestinal Endoscopy, vol. 57, no. 4, pp. 567-579, 2003.

[4] K. Hotta, T. Oyama, T. Akamatsu et al., "A comparison of outcomes of endoscopic submucosal dissection (ESD) For early gastric neoplasms between high-volume and low-volume centers: multi-center retrospective questionnaire study conducted by the Nagano ESD Study Group," Internal Medicine, vol. 49, no. 4, pp. 253-259, 2010.

[5] S. Tanabe, K. Ishido, K. Higuchi et al., "Long-term outcomes of endoscopic submucosal dissection for early gastric cancer: a retrospective comparison with conventional endoscopic resection in a single center," Gastric Cancer, vol. 17, no. 1, pp. 130-134, 2014.

[6] K. Okada, T. Tsuchida, A. Ishiyama et al., "Endoscopic mucosal resection and endoscopic submucosal dissection for en bloc resection of superficial pharyngeal carcinomas," Endoscopy, vol. 44, no. 6, pp. 556-564, 2012.

[7] J. Y. Ahn, H. Jung, J. Y. Choi et al., "Endoscopic and oncologic outcomes after endoscopic resection for early gastric cancer: comparison of absolute and extended indications," Gastrointestinal Endoscopy, vol. 74, no. 3, pp. 485-493, 2011.

[8] J. C. Park, S. K. Lee, J. H. Seo et al., "Predictive factors for local recurrence after endoscopic resection for early gastric cancer: long-term clinical outcome in a single-center experience," Surgical Endoscopy, vol. 24, no. 11, pp. 2842-2849, 2010.

[9] K. Watanabe, S. Ogata, S. Kawazoe et al., "Clinical outcomes of EMR for gastric tumors: historical pilot evaluation between endoscopic submucosal dissection and conventional mucosal resection," Gastrointestinal Endoscopy, vol. 63, no. 6, pp. 776$782,2006$.

[10] T. Shimura, T. Yamada, M. Sasaki, H. Kataoka, and T. Joh, "Advantages of endoscopic submucosal dissection over conventional endoscopic mucosal resection for intramucosal gastric neoplasms," Gastrointestinal Endoscopy, vol. 65, no. 5, p. AB169, 2007.

[11] S. Nakamoto, Y. Sakai, J. Kasanuki et al., "Indications for the use of endoscopic mucosal resection for early gastric cancer in Japan: a comparative study with endoscopic submucosal dissection," Endoscopy, vol. 41, no. 9, pp. 746-750, 2009. 
[12] F. Catalano, A. Trecca, L. Rodella et al., "The modern treatment of early gastric cancer: our experience in an Italian cohort," Surgical Endoscopy, vol. 23, no. 7, pp. 1581-1586, 2009.

[13] B.-H. Min, J. H. Lee, J. J. Kim et al., "Clinical outcomes of endoscopic submucosal dissection (ESD) for treating early gastric cancer: comparison with endoscopic mucosal resection after circumferential precutting (EMR-P)," Digestive and Liver Disease, vol. 41, no. 3, pp. 201-209, 2009.

[14] S. Hoteya, T. Iizuka, D. Kikuchi, and N. Yahagi, "Benefits of endoscopic submucosal dissection according to size and location of gastric neoplasm, compared with conventional mucosal resection," Journal of Gastroenterology and Hepatology, vol. 24, no. 6, pp. 1102-1106, 2009.

[15] S. Hoteya, T. Iizuka, M. Hashimoto et al., "The safety and efficacy of the endoscopic submucosal dissection for early gastric cancers, compared with conventional endoscopic mucosal resection," Gastrointestinal Endoscopy, vol. 65, no. 5, p. AB358, 2007.

[16] I. Oda, D. Saito, M. Tada et al., "A multicenter retrospective study of endoscopic resection for early gastric cancer," Gastric Cancer, vol. 9, no. 4, pp. 262-270, 2006.

[17] S. Oka, S. Tanaka, I. Kaneko et al., "Advantage of endoscopic submucosal dissection compared with EMR for early gastric cancer," Gastrointestinal Endoscopy, vol. 64, no. 6, pp. 877-883, 2006.

[18] K. S. Choi, H. Y. Jung, K. D. Choi et al., "Endoscopic submucosal dissection for gastric tumors: complete resection rate, resection time and complications in comparison with endoscopic mucosal resection after circumferential mucosal incision with a needle knife[J]," Korean J Gastrointest Endosc, vol. 32, no. 5, pp. 326-332, 2006.

[19] M. Odashima, M. Otaka, M. Jin et al., "Improved curative resection rates of early gastric cancers by Endoscopic Mucosal Resection (EMR) using Endoscopic Submucosal Dissection Method (ESD)," Gastrointestinal Endoscopy, vol. 63, no. 5, p. AB187, 2006.

[20] C. Yokoi, T. Gotoda, H. Hamanaka, and I. Oda, "Endoscopic submucosal dissection allows curative resection of locally recurrent early gastric cancer after prior endoscopic mucosal resection," Gastrointestinal Endoscopy, vol. 64, no. 2, pp. 212218, 2006. 


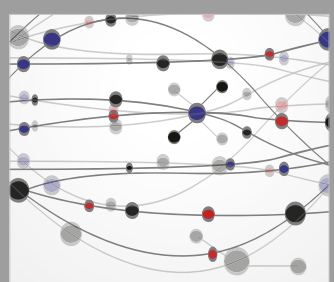

The Scientific World Journal
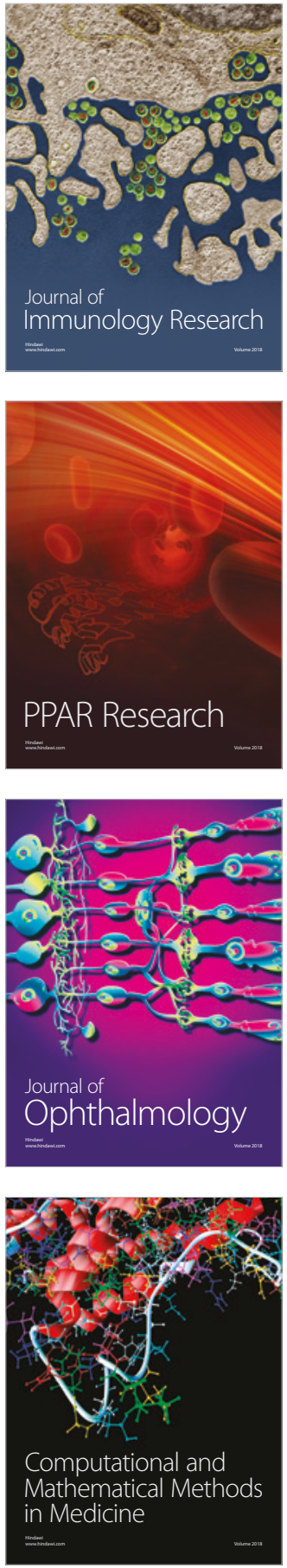

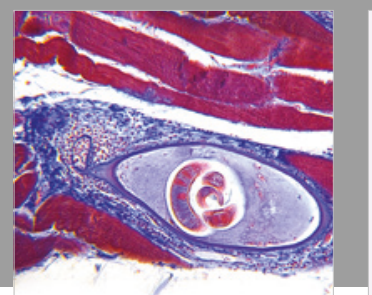

Gastroenterology Research and Practice

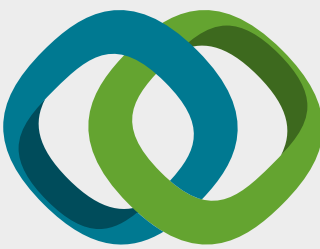

\section{Hindawi}

Submit your manuscripts at

www.hindawi.com
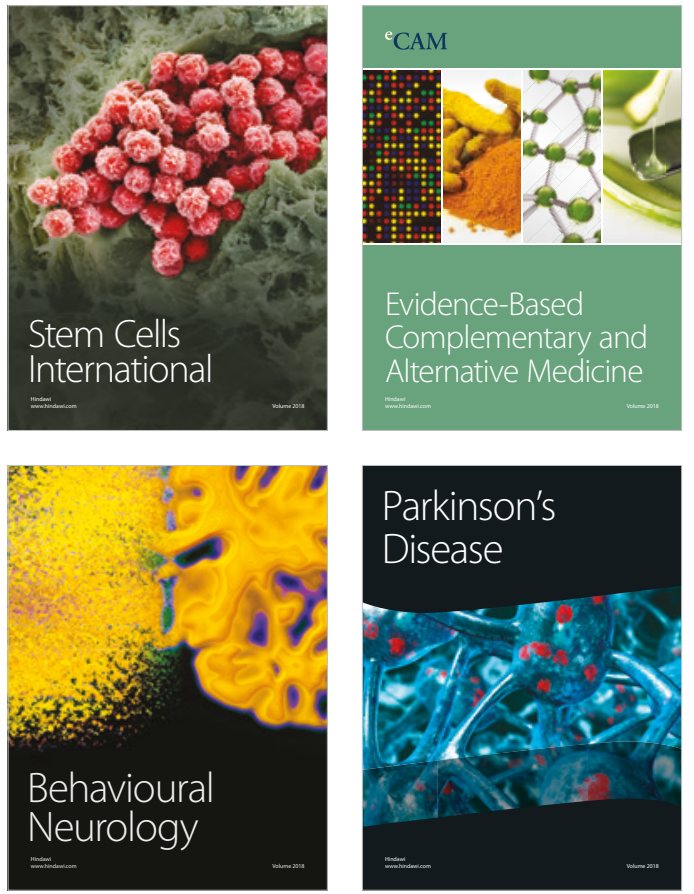

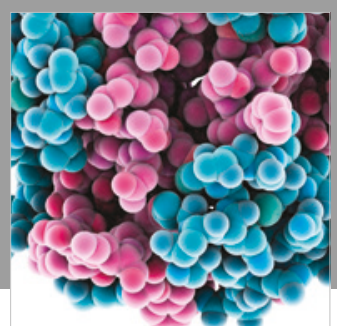

ournal of

Diabetes Research

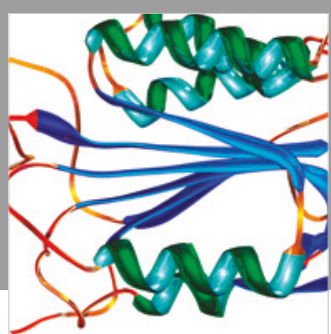

Disease Markers
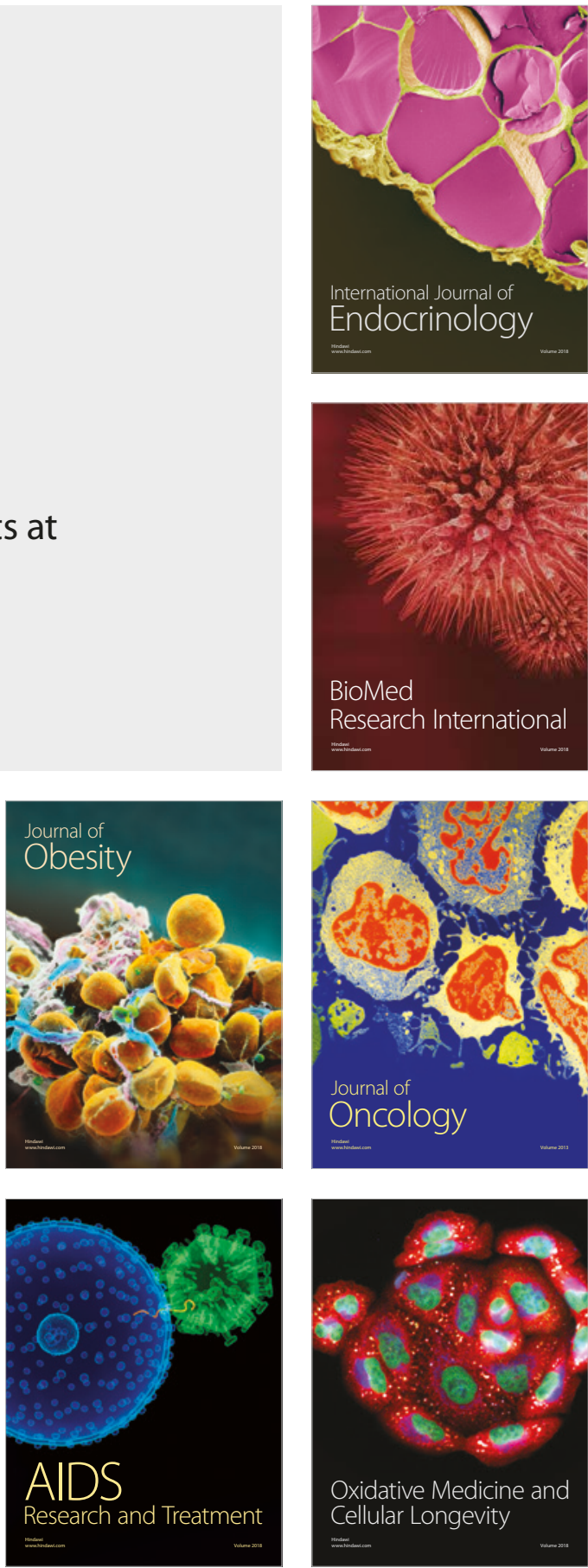